\title{
SAFETY AND SYSTEMS ANALYSIS, WITH APPLICATIONS TO TRAFFIC SAFETY
}

\author{
David M. Boodman*
}

Much that goes on in the world today is described in terms of systems. There seems to be increasing recognition of the fact that very little of the more important kinds of human activity takes place in isolation; so interconnected and interdependent have these activities become that it is standard practice today to look beyond the immediate inputs and outputs of these activities and to ask about their consequences for the rest of the system. We therefore speak of our educational system, our defense systems, medical care system, transportation system, and economic systems as groupings of related activities. We ask ourselves about the goals of these systems and the resources available for operating them. We design these systems to yield us a maximum of whatever objective we have set for them in exchange for the resources we have committed to them.

The scale of concern of the systems analyst and designer varies over a wide range, from the trivially small to the globally large. A military systems analyst may define his area of concern as the defense of naval task forces against submarine attack and thus focus his attention on a limited system containing only submarines, surface and air forces, undersea detection devices, and weapons appropriate to the tactical encounter between offensive submarines and defensive task forces. Another analyst, concerned with the broader objective of defense of the coastal regions of the continental United States, would have a larger system to consider-one containing the complete catalog of detection devices and weapons systems needed to counter the various forms of subsurface, surface, and airborne attack that could be launched.

Whatever his scale of concern, the designer has the task of producing a system possessing a high degree of effectiveness. For a transportation system, which may consist of the network of roads connecting a group of cities, the measure of effectiveness is generally considered to be the cost per ton of cargo or per passenger moved in this network. The systems designer, accordingly, lays out roads, sets traffic controls, and in general arranges facilities and services which yield as low a cost per unit of transportation as possible.

Submerged in the details of design considerations and generally not given explicit recognition is the question of safety. The unstated constraint on the quest for economical and efficient transportation is a requirement that the planned movement

* B.S. 1944, Ph.D. 1950, University of Pittsburgh. Senior Staff, Arthur D. Little, Inc., Cambridge, Mass. Co-author [with J. F. Magee], Production Planning and Inventory Control (2d ed. 1967). Contributor, Arthur D. LtTrle, Inc., State of the ARt of Trappic Safety (1966), and Artiun D. Little, Inc., Cost-Effectiveness in Traffic Safety (ig68). 
of goods and people be accomplished with as little loss of life and limb as possible. Some adjustments are made in roadway layout to limit the sharpness of curves or other hazardous roadway features; traffic control is arranged to avoid risky situations during periods of heavy traffic. A compromise is made in the cost of transportation in the interests of restricting the "costs" of accidents.

A system is defined by the machinery, the people, and the procedures assembled and organized for the accomplishment of a specific task within a specified environment. In the previously described transportation example it is necessary to specify not only the vehicles and roadways but also the rules of operation and the operators themselves in order to describe the transportation system. The safety of the system is measured by the ability of the system to perform the tasks for which it was intended without experiencing losses due to accidents. Accidents are failures of the system, failures which have their origin in the physical apparatus of the system, in the people involved in the system's operations, in the procedures for operating the system, or in the environment in which the system operates. An accident occurs when the system fails due to a stress that exceeds the system's ability to withstand it. Safety, in short, is concerned with the pathology of systems.

The particular pathology that leads to traffic accidents has recently begun to attract considerable public attention. There is growing recognition of the complexity of the traffic safety problem and its many-sided nature. It has become widely appreciated in recent years that automobile accidents are basically failures of a system and that it is meaningless to speak of simple causes of vehicle accidents. There are system features that can be broadly grouped and identified with either the vehicle, the environment, or the driver. These features contribute to the creation of the accident event (first collision), the damage and injury in the accident (second collision), and the degree of loss after the accident (postcollision phase). Every one of these features, and many combinations thereof, can be viewed as contributory to the accident loss. In this view, the possible causes of the loss in an accident in which, for example, a driver loses his life because his car left the road on a curve and overturned, include the condition of the road surface, the condition of the vehicle's tires, the vehicle's suspension, its speed, its brakes, road signs warning of the curve, various perceptual and motor-control features of the driver, and the medical support provided the injured driver in providing him first aid and removing him to a hospital. By this same view, it is possible to consider as a countermeasure to this class of accident, changes in any of several of these factors. Thus, if a particular feature of the system appears to be affecting the accident rate unduly, changes can be made in that feature or in another element of this system that compensates for it. If smooth tires are believed to contribute to loss of control on the road curve, resurfacing of the road or straightening the curve or the appropriate emplacement of warning signs may be able to accomplish a reduction in accident rates which a more rigorous 
inspection of vehicle tires cannot. The desirable remedies are those which produce the greatest reduction in accident loss for the expenditure made on the remedy itself.

Our present ability to mount effective programs aimed at the reduction of traffic accident loss is severely limited by our lack of understanding of the many factors affecting the safety of motor vehicle operations. A recent examination of the factors contributing to traffic accidents has documented the meager understanding that exists at present of these many safety factors. This study noted that an effective attack on the traffic safety problem will require the following: ${ }^{1}$

I. Recognition of the complexity of the problem. There are many factors of the environment, the vehicle, and the driver affecting traffic safety; no single factor can be identified as a principal "cause" of accidents.

2. Proper identification of remedies or countermeasures. An understanding of the factors contributing to accident loss is necessary for the identification of effective remedies.

3. Selection of remedies on the basis of the improvement produced for the expenditure made. The resources available for traffic safety improvement are not without limit, and it is therefore necessary to allocate the funds available for this purpose in a way that yields the greatest gain possible in terms of accident loss reduction.

We proceed now to describe the nature of the safety problem in our automotive transportation system and the possible contribution that systems analysis can make in dealing with this safety problem. We will describe the traffic safety problem and summarize the current factual information available for the analysis of this problem. We will then show what inferences can be drawn from the facts available on the causes of traffic accidents and the implications for the direction of efforts aimed at the reduction of traffic accident losses and the equitable distribution of the economic burden of these losses.

The Traffic Safety Problem

When we speak of traffic safety we refer to the traffic that is represented by the movement of people and commodities in vehicles on our public and private roadways. Very simply defined, traffic safety is the degree to which this movement can be accomplished without injury or loss of life or property. Safety, in other words, is one of several requirements that we place on our traffic system. This transportation system has a job to do in the movement of people and commodities; we desire that this job be accomplished with the least possible hazard to life, limb, and property consistent with its accomplishment.

One view of the toll taken by the traffic system is presented by the National Safety

\footnotetext{
${ }^{1}$ Arthur D. Litille, Inc, State of the ARt in Traffic Safety 31-32 (1966).
} 
Council.' The I966 death toll in the United States was approximately 53,000, an increase of some five per cent over 1965. In addition to those fatally injured in automobile accidents there were nearly $2,000,000$ persons injured including perhaps I00,000 permanently disabled. By itself, the number of deaths does not present a complete picture of the loss. Accidents are a leading cause of death for all ages up to age forty-five, and motor vehicle accidents are the single largest cause of death in the fifteen to forty-four age group. In the fatal accident category, collisions between motor vehicles were the most numerous, followed by noncollision in roadway or overturning or running off the roadway, all of which together accounted for approximately seventy per cent of total fatalities. Pedestrian accidents, collisions with railroad trains, bicycles, fixed objects, and miscellaneous other accidents accounted for the remaining thirty per cent. The total annual dollar cost associated with traffic accidents, according to the National Safety Council, is approximately \$ro billion, including the loss of earnings to those who were injured or killed, medical expense, property damage, and insurance overhead but not including the pain, fear, and suffering associated with those losses. This is equivalent to approximately eight per cent of the total annual cost of motor vehicle transportation. Our accident cost, in other words, amounts in good round terms to between one and two cents per mile.

There is, of course, no rational way of establishing an acceptable level of accident loss in our transportation system. We can observe the numbers of different types of accidents and the losses associated with each from year to year; we can normalize these losses by taking account of the amount of exposure to accidental loss occurring in each period by dividing these losses by the number of vehicle-miles or passengermiles or numbers of vehicles or population totals or any other agreed-upon measure of exposure. On one basis or another we can decide whether the hazards of traffic systems operations are increasing or decreasing. Such arguments, however, are almost totally beside the point in the current concern over traffic safety. Since we cannot define an "acceptable" level of traffic loss and since we cannot identify the appropriate measures or exposure to hazard in traffic operations, then the most that can really be said about accidental loss in traffic systems operations is that we as a nation are willing to accept this loss or that we wish to reduce it. Fundamentally, then, we have a traffic safety problem because we say we have a traffic safety problem. We can compare our loss experience from year to year, or with that incurred in other countries, and obtain relative measures of performance, but we cannot use these measures of performance to prove that we have a traffic safety problem.

If, on this basis, we agree that we have a traffic safety problem, then our next concern is that of identifying programs of action that will reduce our losses in traffic accidents. Recognizing that the changes we would make in the vehicle, in the driver, in the roadway, and in the other elements of our traffic systems operations,

\footnotetext{
${ }^{3}$ National Safety Council, Accident Facts 3, 40-71 (I967 ed.)
} 
all require expenditures of financial resources, and therefore recognizing that we cannot do everything, we have to ask how we find the programs and actions that will provide the greatest effectiveness in terms of reduced losses due to accidents for the resources expended on those programs and actions.

Many proposals have been advanced for the improvement of traffic safety. Many individuals and agencies over the past several years, sincerely interested in the problem of traffic safety, have spoken very forcefully about programs required, if not guaranteed, to improve traffic safety. Some have argued for extensive improvement and modifications of the automobile, in some instances urging total redesign of the vehicle, to provide what some believe will be a crashworthy car, capable of providing protection to occupants in head-on collisions of velocities up to fifty miles an hour. Others have argued for more stringent enforcement of stricter traffic laws and the imposition of more severe fines and penalties for infractions of these laws in the belief that tighter law enforcement will deter a small number of drivers in whom a disproportionate amount of our accident experience is concentrated. Still other agencies have urged that drivers be better prepared and selected for licensing, again in the belief that such care in screening the driving population will enable us to cull out those drivers or potential drivers who, because of measurable and observable physical and physiological attributes can be identified as contributing a disproportionately large share of the total accident risk in the driving population.

In the face of these many claims for effective programs for the improvement of traffic safety, the agencies responsible for the improvement of safety are confronted with the difficult task of making decisions regarding the selection of programs or mix of programs and the amount of support to give to each. The extreme delicacy and importance of the traffic safety problem in the United States make it necessary that these programs be properly considered and thoughtfully evaluated before making a major commitment to any of them.

The thoughtful decision-maker encounters serious obstacles. He hears the various claims of the designers of crashworthy cars, law enforcement officials, driving educators, and others who may present entirely credible arguments for their particular remedies. But the responsible decision-maker, knowing that he is being asked to make irrevocable commitments of resources to changes in the motor vehicle system, has to ask: "What will your particular remedy do and how much will it cost? Is it worth more than it costs and, since there are several remedies competing for the same life- and injury-saving job, which one does the job best?" He knows that his decisions will have serious impact on government, industry, and the public, and he wishes to act wisely.

Systems analysis provides an approach to traffic safety that assists in the making of these decisions by systematically applying as much of the quantitative information as is available on the subject. Its special relevance to traffic safety and other largescale public policy problems is described in what follows. 


\section{II}

\section{Systems Analysis of Public Policy Problemss}

Systems analysis is operations research applied at the strategic level. Operations research formally came into being in the early days of the Second World War as an attempt to apply the methods of the physical and mathematical sciences to operational problems of warfare. A number of organizations in the British military establishment and, later, in the United States Navy set out to solve problems of sonar search for submarines, maintenance of sorely needed aircraft, and tactical deployments of limited fighter aircraft forces, by formally applying scientific methods to the quantitative, measurable parts of these problems. ${ }^{3}$

Operations research provided useful and important answers to extraordinarily complex questions such as how a ship should maneuver to evade attacking kamikaze planes. In spite of all the efforts to keep Japanese aircraft from penetrating outer defenses, suicide planes were able to make successful attacks on our naval units in the latter stages of the war. The commanders of units under attack had to decide either to dodge the attackers by undertaking violent maneuvers or to maintain a steady course in the hopes that antiaircraft fire could destroy them. They could not do both. Their problem was the selection of the appropriate tactic which would minimize the chance of being hit. An operational analysis of several hundred recorded episodes of suicide attacks showed the percentage of ships hit by the suicide aircraft for both maneuvering and nonmaneuvering ships. Maneuvering was of considerable help for the larger ships-battleships, cruisers, and carriers-while for the smaller destroyers and auxiliaries it was a liability. Correspondingly, the effect of maneuvering on the accuracy of the antiaircraft fire of the large ship was very slight, while for the small ship maneuvering virtually destroyed its effectiveness. Additional analysis of the earlier episodes provided further information of the preferred orientation of the ship for the attack. The dimensions of the target presented to the attacker were of great importance and depended on whether the suicide aircraft made a steep high-dive attack or a horizontal low-altitude attack. Such straightforward, quantitative analysis of the problem was of great benefit. It was subsequently found that only twenty-nine per cent of the suicide attacks on ships using the recommended tactics were successful, whereas forty-seven per cent of such attacks had previously found their targets.

As the operations being researched became better understood by the analyst, a need was felt for better methods of analysis, and, with the end of the war, there came an opportunity to devote effort to the building of a body of theory useful in the solution of operational problems. Operations research captured the imagination of many competent scientists both in the United States and abroad, and considerable attention was given, in the decade following the Second World War, to the development and

\footnotetext{
The history is recounted in P. Morse \& G. Kimbarx, Methods of Operatrons Research I-II (I95I).
} 
application of advanced methods of statistics, mathematical analysis, stochastic processes, and mathematical programming to the solution of operational problems. Later, the high-speed, stored-program, digital computer made its appearance to add additional dimensions to the capabilities of the operations analyst by providing him an ability to capture and process information rapidly and at relatively low cost. Simulation with mathematical models of the operations under study became possible, and problems too difficult to treat analytically became soluble by Monte Carlo or random trial methods.

Concurrent with this expansion of operations research methods, there was an extension of activities into other areas of the civil and private sectors. Many of the methods developed for the solution of military problems were found useful for the solution of governmental and industrial problems. The mathematics of queueing theory, developed for the analysis of congestion situations, explained not only the behavior of ships waiting to unload at Korean docks in 195I; it also explained the behavior of such phenomena as single-lane, nonpassing traffic on the bridges and tunnels in New York City in 1953 and the distribution of waiting times for inquiries into an airline reservation system in 1960 .

In the early I950s these methods had begun to be applied to a broad spectrum of problems in American industry. Scientific methods found wide application to the analysis of problems in marketing, distribution, production, and financial operations of the firm. With the aid of the insights developed by such analysis of these operations, it became possible not only to obtain refined solutions to operating problems but also, through the use of control systems techniques, to continue to apply these solutions routinely to the firm's operations in the face of continuing changes in these operations. Use was made of the methods familiar to the mathematician and the electrical engineer in developing control systems for production, distribution, and marketing operations. There are literally hundreds of these now in operation in the United States, providing operating economies for firms of all sizes.

As indicated earlier, systems analysis is simply the extension of operations research to problems at the strategic level. It is distinguished by the size and complexity of the problems with which it deals, not in the methods it employs or the approach it takes to the solution of these problems. Systems analysis grew out of operations research as a result of the repeated re-examination of objectives. In dealing with problems at the tactical level, the analyst continued to ask himself about the appropriateness of the solution he was obtaining to these problems. Was he in fact solving the right problem? Was the solution he was obtaining providing the desired objectives or were these objectives being obtained at the expense of more important objectives? In designing an inventory control system, for example, were economies of inventory operations being obtained at the expense of the production or marketing operations to which these inventions were related? If so, could a better objective function for the problem be found so that the system's total objectives 
could be satisfied? In studying the problem of submarine attack against overseas shipping, should the analyst concentrate efforts on the development of search tactics for submarines, or should he examine the larger question of the protection of overseas transport and decide whether or not the objectives of antisubmarine warfare are to maximize the number of submarines sunk or the tonnages of cargo safely transported across the oceans?

By continuing to ask if he is solving the right problem and by showing that he can help to identify the right problem, the analyst has been invited to look into the larger problems of the whole system and to bring to bear any of his methods that prove useful in dealing with these systems problems in industry, in government, and in defense. ${ }^{4}$ The analyst, then, becomes a systems analyst; as a systems analyst, aware of the strategic nature of the problem, he is still ready to solve the separate smaller tactical problems contained in the strategic problem. He is, however, fully aware that there are nonquantifiable elements in the systems problem that will not yield to the quantitative treatment so familiar to him in dealing with tactical problems. There are softer parts to the systems problem that do not behave as predictably as the physical and mechanical parts of the tactical problem. The advice and the assistance of specialists in fields less familiar to the systems analyst must be drawn upon.

The current endeavors of the operations research community display the breadth of application of systems analysis methods. Work is now going on in such areas as crime control and law enforcement, examining such things as strategies for the control of illegal narcotics, scheduling and routing of patrol car operations for a metropolitan police division, and so forth. Work is underway in the public health area, in developing models of the contagion process for diseases such as tuberculosis, to be used in developing strategies for the control and possible eradication of this disease. Urban planning, the poverty program planning, protection against forest fires, educational planning, and metropolitan traffic systems design are other areas of current activity in the operations research community. One of the more recent entries into the field is the problem of traffic safety.

There is a common approach to the solution of all of these problems. Figure I depicts the logic of the approach of systems analysis. First, the objectives of the system must be examined and set forth in sufficiently operational terms so that measures of performance for the system can be developed. Second, alternative methods of satisfying the stated objectives must be sought, and information on these alternatives must be assembled for analysis. Third, the separate alternatives must be evaluated to determine the contribution each could make in satisfying the stated objective and the costs to produce these contributions. That is, the effectiveness of each alternative and the cost that it imposes must be measured. Ultimately, the

\footnotetext{
'Systems analysis is identified in the public mind with Secretary McNamara's administration of the Department of Defense. See Analysis for Military Decisions (E. Quade ed. 1964).
} 


\section{THE PLANNING}

PROCESS IN

\section{TRAFFIC SAFETY}

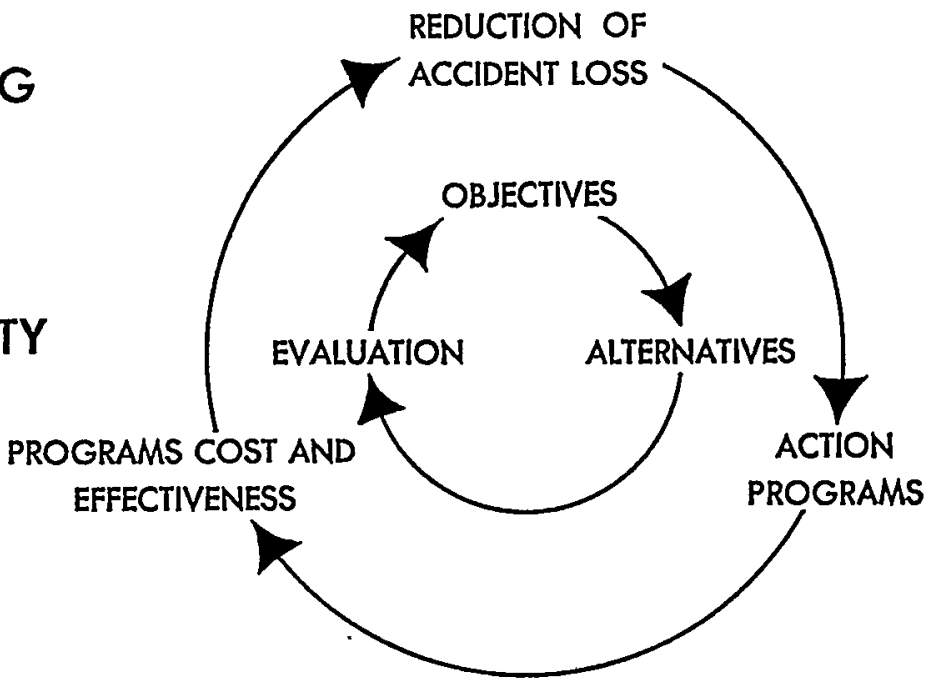

FIGURE I

objectives must be reconsidered in the light of the alternatives available and the capabilities of each. Further iterations through this cyclic process can be made to produce a better match of goals and means.

In the context of the traffic safety problem, therefore, we must decide on our objectives in traffic safety, examine the alternatives by considering the effectiveness and costs of each alternative that can be applied, and select from the list of such alternatives the amounts of each we wish to apply. Perhaps the simplest task in this approach is the matter of the objectives. It is clear that what we seek is a reduction in the total loss experienced in the operation of our traffic system. The loss, of course, includes a mix of fatalities, injuries, and property loss, but it is nonetheless clear that the objective is the reduction of the totality of this loss. The difficulties begin when we start to consider the alternative programs of action available in the search for those that will contribute most efficiently to the diminution of this traffic accident loss.

\section{III}

The Systems Aspects of Traffic Safety

It is not sufficient justification for systems analysis treatment simply to assert that our traffic system is highly complex and that we have to be scientific and quantitative if we are to find a desirable solution for the problem. Others would argue with equal validity that systems analysis is a costly, unnecessary, and time-consuming process for getting from a preconceived notion to a predetermined answer and that we ought to avoid the cost and delay by jumping directly ahead to some of the obvious faults in the system and to make transportation safer by immediately getting to work on these. They could claim that we now know of deficiencies in the 
vehicle, in the driver, and in the highway and that we ought to find immediate remedies for these.

The systems approach is advocated simply because there is strong evidence that the more direct attack on the problem cannot work. Improvement of the safety of today's traffic system requires application of scientific and quantitative methods to the study of both the accident problem and the remedies proposed for its solution. The argument for this position may be summarized in the following postulates:

Postulate I. Accident losses can be reduced. There is ample evidence that the trillion or so vehicle-miles and the almost 400 billion ton-miles of cargo transport that our present transportation system generates annually can be achieved at a lower total cost in fatalities, injuries, and property damage than is now paid. Our present transportation system, in other words, can achieve the objectives for which it was designed and intended much more safely than at present. For example, there is good evidence that separation of the opposing lanes of traffic on rural highways can reduce the fatality rate to about a third of what it now is under unseparated conditions. There is good reason to believe that more frequent and more thorough automobile inspections could reduce accident loss. Traffic circles for intersecting urban flows, clear and firm shoulders along the right-hand road edge, better night-lighting of rural highways-these and many other programs could serve to improve the safety of our present motor vehicle transportation system.

Postulate 2. No single action or remedy will produce a major reduction in traffic accident losses. Traffic safety research historically has taken two routes in search of the magic bullet, or instant remedy: the statistical and the clinical. On the statistical side, the differences in accident experiences among the various segments of our transportation system have been examined-chronological, geographic, economic, and other segments-in the hope that we could sort out statistically the leading variables and attributes of the accident event and the principal causes of accidents. On the clinical side there have been a number of intensive studies of individual accidents, delving deep into the background of the accident situation, in some instances examining in detail the childhood experiences of the drivers involved. Both approaches have failed to isolate any single factor or set of factors the modification or correction of which would drastically reduce accident losses. The remedial actions required to improve traffic safety appear to be a mix of many rather than the intensive application of a few. There is no reason to believe that an instant remedy exists.

Postulate 3. There is a cost associated with every remedial action which could produce a significant improvement in traffic safety. Here we face the problem of scale. Changes made through the automobile must reckon with the fact that there are over eighty million cars of all ages already on the roads and between seven and nine million new ones joining the population every year. Changes to the roadway must reckon with the fact that there are about three million miles of paved rural and urban highway and street to deal with. Changes made through the driver must 
consider the fact that there are ninety-five million licensed American drivers and approximately four million new drivers entering the population every year. The scale of the problem is enormous and has two important consequences: first, the rate of change will be slow, and, second, even small unit costs will become important total costs in any remedial action program. One additional point to bear in mind in considering the costs of safety action programs is that the resources available are not without limit. The efforts, the money, the time, the total resources available for any undertaking directed at improvement of safety are, as in all such cases, limited. We cannot have an endless amount of everything we want. Any resource that we put into improvement of highways is, by that act, not available for the improvement of the vehicle. The resources committed to the improvement of traffic safety will, of course, be drawn from a variety of pockets, private as well as public and corporate; but in the last analysis the total amount committed to this purpose must be considered limited.

Postulate 4. .The ability to select efficient action programs (remedies) is limited by our understanding of the causes of accidents. Accidents are basically a systems failure, and finding the factor the control or elimination of which could have prevented the accident is a very difficult task. In only a limited sense can we speak of causes of accidents; there are factors which the study of accidents can identify as those to be controlled to prevent future accidents. But when we speak of cause we must recognize that there are various levels of understanding of cause. We nced a continual refinement of this understanding in order that we may find the most efficient remedies for this disease. The history of medicine offers many instructive analogies. Bubonic plague carried off some sixty million people in Europe during the Middle Ages. Virtually nothing was known of the disease when the first major epidemic hit in the fourteenth century, except that it came from the east. Little could be done to combat the problem other than to avoid people from the enst and those from the west who had already been stricken. Soon, it was observed that filth and the rats it bred were sources of the disease. Later, the flea to which the infected rat is host was identified as the transmitter of the disease; and ultimately the germ that produces the toxin that causes the disease was identified. As the understanding of the cause advanced, so did the efficacy of the efforts to combat the disease. Appropriate efforts could be devoted to clean up the filth that bred the rats; to exterminate the rats that harbored the flea; to screen and spray against fleas that carry the germ, and in fact to discover and produce antitoxins that immunize against the disease itself. The important point is that the more detailed our observations of the accident process and its results, the more intelligent will be our speculations about contributing factors. The better the assortment of contributing factors we have, the more efficient will be our search for effective remedies.

Postulate 5. The effectiveness of a remedy, in terms of its contribution to the reduction of accident loss, can be measured. Any change in the traffic system can 
produce an effect on the safety of the system expressible quantitatively in terms of the frequency of fatal injuries, personal injuries of a spectrum of kinds, and property damage, per unit of exposure. This effect can be measured directly by means of before-and-after observations of the traffic system, or it can be determined inferentially or deductively, that is, indirectly by measurements not involving accident events. In this last instance the link between a remedial action and the accident rate must be provided by theoretical calculations based on related experimental evidence.

Postulate 6. The cost of a remedial action can be measured. A variety of resources may be required for any remedial action, and a variety of costs, both market and social costs, may be drawn from all components of the system. A median barrier, for example, generates benefits in terms of reduced fatalities, bodily injuries, and property damage, but it simultaneously draws upon resources of a variety of kinds. The obvious costs of the barrier include its initial installation costs and its annual maintenance costs, including the repairs required by the cars striking it; but there may be other costs. Snow removal may be more difficult. Maintenance of the roadway itself may be handicapped and thus made more expensive. A careful economic analysis of all the changes resulting in the system from the application of the remedial program can tell us what the true benefits of the program are as well as the true costs of the program. Both the costs and the benefits can be converted to a time stream of values, and the present value of the benefits can be compared with the present value of the costs in order to select the effective programs and to decide on the quantities of each remedy to be applied.

Postulate 7. The best mix of programs (remedies) can be selected by a careful analysis of the costs and benefits of each proposed remedy. Since the resources available for traffic safety improvement are not infinite it is necessary that the apportionment of the limited effort available among the alternative and competing programs of traffic safety improvement be made with some care. This general approach helps the decision-maker avoid several serious pitfalls, chief among which are the errors into which intuition frequently leads. A recent study of median treatments on California expressways has shown how one form of barrier, believed desirable because it reduced the fatality rate, was in fact undesirable because of the higher injury and property damage rate it created. ${ }^{5}$

Postulate 8. The effectiveness of some remedies may change with time. There are two reasons for instability in the remedies prepared for the reduction of accident loss. One arises from the fact that there are counteracting forces in the system which tend to offset many of the improvements in safety resulting from other changes introduced into the system. This effect has been frequently observed and widely reported. It has been noted for example that when street lights have been installed to improve night visibility, there is an initial improvement in accident experience which is gradually lost due to increasing vehicle speeds. A similar effect is noticed when a

\footnotetext{
"Arthur D. Little, Inc., Cost-Effectiveness in Traffic Safety 85-to6 (ig68).
} 
sharp curve or other road hazard is removed. It may, therefore, be necessary in evaluating effectiveness to distinguish between immediate and long-term accident rate changes. A second source of instability arises from the fact that other changes unrelated to safety are continually being introduced into the motor vehicle system in the form of new model vehicles, new drivers, new or rebuilt highways. In many instances the effects of these changes on safety are not known nor can they be estimated in advance. It may be necessary to determine their effects on purely empirical grounds. For these reasons it seems evident that the traffic safety problem has no permanent solution. Traffic safety is a problem to be managed rather than solved.

\section{IV}

\section{State of The Art}

The systems approach requires an orderly cataloging of the factors affecting or contributing to traffic loss and a quantitative evaluation of the effectiveness and costs of the remedial measures these factors suggest. The information requirements for the successful management of a system as complex as our traffic system would appear to be staggering. Since systems analysis is basically a prescription for an ideal solution of this problem, it is important to ask several questions:

First: Do we have the information necessary for such an ideal solution?

Second: If not, what should we do to fill in the information gaps?

Third: What can we do about traffic safety until these gaps are filled?

The first question has been answered by a detailed investigation published in 1966 of factors affecting traffic safety, which attempted to pull together from the publicly available literature all of the available information bearing on these recognized traffic safety factors. ${ }^{6}$ This study organized the topics into the principal categories of the physical environment, the driver, the vehicle, and the legal and regulatory factors, considering in each case those factors which come into play before, during, and after the accident event. We summarize here the findings of this report on the information presently available on the traffic system factors believed to be important in the accident process. ${ }^{7}$

\section{A. The Environment}

Environmental factors include the physical elements of the roadway and the various other entities of the roadway and the roadside which affect the safety of the movement of the vehicle; a second group of factors consider the informational elements of the environment which provide the vehicle operator with information on his location and instructions for his continued travel; and a third group consists of

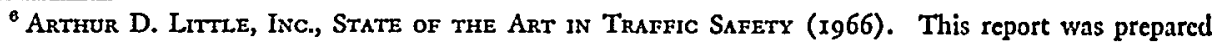
for the Automobile Manufacturers Association.

7 The facts and conclusions contained in the following discussion are taken from the report, which surveys some 2000 published sources and provides extensive documentation of the matters here summarized. 
special informational factors-operational control factors relating to the control of speed, direction, and vehicle restrictions.

Roadway. There is a useful amount of information available on the various aspects of the roadway. There is good evidence to show that the alignment features specified for the interstate highway system have been one of the significant contributors to the favorable accident experience on these highways. There is additional British information on the effectiveness of spot improvement programs in elimination of hazards in existing roads through realignment and improvement in superelevation of the roadway.

Surface. With regard to the road surface itself, a study has shown that only slight improvement in road accident statistics results from improved maintenance of shoulders and elimination of holes, ruts, and bumps. Efforts at such improvements above the present levels have not produced significant effects on road accident rates. Loss of adhesion, however, remains a factor of major importance in the safety problem, and the surface characteristic of principal concern appears to be the frictional property of the road surface, wet and dry. While we have good information on the number of accidents in which skidding appeared to be a factor we do not have information on the number of accidents initiated by skidding events.

Roadside. There is a substantial literature on the subject of the effects of the roadside on accident rates, which establishes quite well the fact that safe separation of opposing streams of traffic requires median widths of fifty feet or more; where land use considerations limit median strips to less than fifty feet, physical barriers must be used to provide a compromise between an increase in the accident rate due to the presence of the barrier itself and a decrease in fatality rate due to the reduction in head-on collisions. The value of a clear roadside at the right-hand edge of the road in reducing the over-all accident rate has also been adequately established. Firm shoulders, gradually sloped drainage ditches, roadside areas cleared of trees and poles, and sign supports designed to be yielding on impact can do much to reduce the consequences of the rather large number of single-vehicle accidents in rural areas.

Road discontinuities. The coverage of this group of factors is relatively spotty and much of the attention has been given to the ramps and exits of rural highways and expressways with little attention to the driveways and intersections of the urban roadway. Freeway ramps have been well examined and reported in the literature. The effects of various ramp heights and geometries on accident rates seems to be well documented. But there is relatively less information available on other forms of discontinuity such as intersections, transitions, turning lanes, and traffic circles, in spite of the fact that these are more numerous and more frequently used.

Visibility. The literature of visibility is not complete enough to answer the many questions about the effects on accident rates of illumination, meteorological and atmospheric effects, and physical obstructions to visibility. Driving at dark 
is more hazardous as the statistics show, but the contribution of darkness to this increased hazard is not at all clear. With regard to artificial illumination over highways, a series of before-and-after trials on a number of highways indicate significant reductions in accident and fatality rates after illumination of any kind is provided. Some of the present visibility problem is known to be due to the reductions in driver eye-height resulting from the lowering of vehicle vertical dimensions in recent years. But the effects of visibility, although known from the geometric point of view, are not known as to their effects on the accident rate.

Communications and signalling. Communicating and signalling with the drivers of vehicles is an imperfect art. There is little agreement in the literature as to what kinds of messages are needed or where these messages are to be placed for maximum effectiveness and safety. The laws of the various jurisdictions with regard to roadway signing are at considerable variance with each other. Although it is agreed that with the advent of more mileage of high-speed unidirectional traffic flow, signs and their placement are of great importance in maintaining safe traffic flow, very little can be said about their quantitative contribution to traffic safety.

Operational traffic control. Traffic control as we use the term here is exercised essentially through control of speed, control of direction, vehicle restrictions, and right-of-way specifications. Each of these is intended to expedite the flow of traffic with a minimum hazard to that traffic. The literature on this topic points up this group of factors as one of the most unsettled areas of traffic safety. There is conflicting evidence gathered from all parts of the world on the effects of speed control and right-of-way control, particularly stop lights, on accident rates.

For the most part, then, the total information on environmental factors is considered poor, and we can consider it reasonably complete only with regard to the factors of the roadway and roadside.

\section{B. Human Factors}

Under human factors, we have considered the biographical facts about the driver, such as age, sex, marital status, and the like; skill factors, that is, those features of the driver in his motor control and perceptual apparatus that enable him to make strategic and tactical decisions in operating the vehicle; medical factors including diseases, impairments, addictions, and the effects of drugs and stimulants on his vehicle-handling capabilities; personality factors; the effects of his training as a driver; and a special group of drivers, the vehicleless driver, the pedestrian.

Biographical factors. Possibly because these are the easiest to collect, biographical data seem to be abundantly available, and many studies are available reporting accident rate correlations with each of the biographical factors of interest. Such data show, for example, that male drivers under twenty-five have more accidents per driver than the average. However, as is the case with most such studies, exposure information is usually missing, and it is not possible to establish the relative hazard that 
each of these biographical factors presents. Numerous correlations have been made between accident records and other biographical factors, but it is usually the case that the correlation is so weak that a major improvement in traffic safety cannot be achieved by the identification of a small fraction of drivers on the basis of their biographical factors, such as driving records, and removing them from the driving population.

Driving as a skill. The work done in this area is extremely complex, and most of it has been aimed at the instrumented vehicle and the experimental psychological approach. Its history is too short to define the role of driver motor control and perceptual capabilities in the accident process.

Diseases. The information on the degree to which disease conditions contribute to the risk of traffic accidents is poor. Admittedly, research into this area is difficult. Studies have indicated that persons with such chronic diseases as epilepsy, diabetes, circulatory disorders, and mental illness may have roughly twice the number of accidents as those free of these diseases. The results are not extensive enough to be considered reliable, and a number of studies have presented conflicting results. The degree to which factors other than the diseases themselves may have influenced the results is not clear. One fact that seems to have been established by these studies is that the sudden seizure effect associated with such diseases as epilepsy and cardiovascular disease does not appear to be sudden enough to prevent a driver from bringing his vehicle to a safe stop. The dangers of sudden seizure seem to be exaggerated.

Physiological impairment. Limited vision or hearing, missing limbs, and so forth, would seem to produce a subpopulation of drivers of special risk. However, there is no evidence in the literature examined to support the belief that this subpopulation presents a special hazard. In fact, compensatory effects seem to develop to offset these deficiencies, at least in the case of drivers aware of their impairments, with the result that the accident records of this subpopulation is comparable with that of the average population of drivers.

Drugs and chemical agents. Much of the work reported in this area deals with the physiological responses associated with drugs and chemical agents rather than with their direct relationship to accident rate. It must be recognized that drugs are taken legally for therapeutic reasons as well as illegally for psychological reasons. In the legal case there are probably many drivers who could not function as well and whose accident rates would be worse without the support given them by these therapeutic drugs. In the illegal case, the limited studies that have been made on persons illegally taking narcotics, hypnotics, and sedatives indicate that their accident records are not significantly worse than the total population, although the results are by no means definitive. The little work that has been reported thus far on the role of carbon monoxide and cigarette smoking as a factor in automobile accidents is not enough to establish the role or possible role of these agents as accident factors. 
The available evidence indicates that carbon monoxide levels in the blood sufficient to produce symptoms of impairment are rare and, in the case of smoking, that the denial of smoking to one who is habituated might in itself produce an adverse effect on his accident rate.

Alcohol. The role of alcohol is fairly clear. It is an important contributor to the hazards of traffic, and a body of literature is growing to support the belief that it is a major factor in fatal accidents. The blood alcohol levels of the accidentinvolved drivers show a significantly higher distribution than those among noninvolved drivers. The chronic alcoholic is a separate sort of problem, although the distinction between the infrequent heavy drinker and the chronic alcoholic is not clear and is difficult to make. There is evidence that the chronic alcoholic who has not been drinking will not have an accident rate significantly higher than the general driving population. The evidence continues to mount that the role of alcohol in the more serious accidents is very high, although it seems to play a lesser role in the less severe accidents.

Personality. The search for attitudes and other psychological attributes of personality which can be correlated with accident rates has had very limited success. Studies in this area are costly, and results are difficult to obtain because of the complexity of the subject matter itself. This is one of the less well developed areas of study in psychology, and the very methods to be used in establishing these correlations are themselves in need of development. In short, it is not possible to apply these tests generally and reliably to sort out those on whom we wish to impose restrictions in the interest of improved traffic safety.

Driver education. Much of the work reported in this area relates to the results of studies evaluating high school driver education. While it can generally be shown that those who have taken driver training courses as an elective have a superior accident record, it is not at all conclusive that this is in fact a result of the training program itself. Students who elect to take high school driver courses appear to be psychologically different from those who do not, and the question of selfselection here remains unanswerable. In traffic safety the question of driver training goes beyond the simple mechanics of operating a motor vehicle. It must also prepare the driver to meet emergency situations in an effective manner, but the entire mattcr of what to teach and how has not yet been fully explored.

Pedestrians. Very nearly one-fifth of our traffic fatalities are pedestrians, and we have a good description of who they are. Pedestrian fatalities in traffic generally are children, the elderly, and those who have been drinking. Our understanding here is basically descriptive. We know we have to separate pedestrian traffic and motor vehicle flow, and we know we can accomplish this with a variety of means such as foot bridges, tunnels, sidewalks protected from the roadway, special play areas, and the like. But beyond this very little else is known of the pedestrian traffic accident problem. 
With regard to our understanding of the role of human factors in traffic safety, the state of information is not particularly good. We can say that alcohol is a major villain, but we cannot say we know what to do about it. We cannot yet identify the "bad" or high-risk driver, and if we could we are not sure we would know what to do with him.

\section{Vehicle Factors}

We consider the effect of the vehicle's characteristics in both the first and second collisions-that is, its possible contribution to the creation of the accident event in the first place and to the seriousness of the ensuing loss-death or injury-once the accident occurs.

Sensory. Sensory factors relate primarily to drivers' vision and include those things affecting the driver's ability to see and be seen: glazing, headlighting, his vehicle's shape, color, and signal lights, his horn, and so forth. Much of the literature in this area describes good design practice in recognition of the importance of these factors, but there is very little that relates these factors, or deficiencies in them, to hazards or accident rates.

Layout factors. Here we refer to the fit of the driver to his vehicle and its control mechanisms. Enough is known about man and how he works (at least mechanically) to say something about how his car and its controls should fit him. There is nothing to show what the contribution or special hazards of misfit are or have been. There is the added problem that, anthropometrically, man is a random variable; the mass production of an automobile that will fit ninety-five or even ninety per cent of the drivers in the United States is virtually impossible, without custom adjustments.

Dynamic control factors. Acceleration, steering, and aerodynamic stability are features of the vehicle formed by its engineering design. These features must be matched to the capabilities of the driver. The theory underlying dynamic control is not well enough developed to make it possible to foretell the characteristics of the complete automobile. Much must therefore be done on a cut-and-try basis, and some bad tries have resulted. How bad and at what cost in accidents, no one knows. We can agree that it is an important set of factors, but we cannot say we know how important.

Vehicle condition factors. Defects arise in a vehicle either because of bad original design, improper manufacture (quality control defect), or age (normal or abnormal wear). Obviously, some accidents are due to mechanical failures, and some are not. But which ones and of what severity and for what reasons, we do not know. The life history of the vehicle after it leaves the factory is in need of study to reveal whatever weakness it may have in actual use. Better postaccident investigation is needed to determine if, in fact, a component failure precipitated the accident.

Brakes and tires. Brakes and tires are the special components whose failures are 
particularly hazardous. Much of what has just been said about components in general applies as well here. Wheel-locking under heavy braking contributes significantly to the skidding problem described in connection with the roadway. But one of the most serious brake problems appears to be neglect: sixty-eight per cent of several hundred randomly selected cars were found to "need" brake work. The safety hazard this represents is not clear since the standards applied were not specified, but it is clear that there must have been a substantial number with safety implications. There are no corresponding data on tire condition, but there have been claims by several state highway agencies that tire failures cause ten per cent of reported accidents.

Vehicle factors-impact phase. This is an area of great complexity and one which has precipitated much debate. To what extent would injury have been attenuated or totally prevented if the vehicle had been modified, that is, equipped with softer fittings, restraint systems, energy-absorbing fore-and-aft sections, thicker glass, more secure door latches, and so on? Much of the reported information derives from examination of accidents and their victims and points to changes that might have lessened the loss. Integrity of the passenger compartment, secure doors, and shoulder harnesses are beneficial and desirable. While we know the direction in which we should move we are not certain how we should build these features, nor have we any good idea of what reduction in accident costs we will get. Over-all, the vehicle is another unknown quantity.

\section{Loss-Limiting Factors}

These factors include those special features of the environment that enable prompt detection, response, and treatment of the accident and its victims and thereby reduce the loss resulting from the accident. This is a new but important safety measure. We know that the rural accident victim is four times as likely to die as his urban counterpart, in spite of the fact that his injuries are less severe and of the same anatomic distribution. We also have the estimate by the World Health Organization that perhaps twenty per cent of the fatalities could be prevented by simple treatment en route to hospitals, chiefly the relief of blocked air passages by simple suction devices.

\section{E. Legal and Regulatory Factors}

The legal and regulatory factors consider the contribution to traffic safety that can be made through tighter regulation of the driver, the car, and the environment.

As far as drinking drivers are concerned, we know that alcohol is a factor in the majority of fatal accidents, perhaps two-thirds of them. But while we have been able to describe the problem, we have not been able to prescribe a remedy. This is a problem that has deep social and psychological roots. The Scandinavian experience with this problem suggests that we are not likely to have a quick victory here. 
The matter of the value of enforcement of traffic regulations-speed laws in particular-is as unsettled as the effect of speed itself on accident rates. The few comparative studies that have been made have tried to relate the accident experience in particular regions or at particular times to the level of police patrol effort in those regions or at those times. The results obtained to date are ambiguous and contradictory. Patrol effort is expensive, and two things are needed here. First we must determine its effectiveness in accident reduction, and, second, we must explore the tactical question of its deployment. Much of it appears to be deployed when and where it is least needed.

Penalization is an uncertain factor. To be effective in accident reduction, the law must define the hazardous operations it wishes to proscribe. Then it must know the deterrent effects of the various levels of jail sentences and fines. And none of this is clear. What we do know is that the present load on the legal and judicial system is extremely burdensome, and adding further to his load could imperil the entire legal process.

Driver training and retraining faces the same uncertainty described earlier in connection with the driver. Whether it is handled in school or by the courts, we still do not seem to know what to teach.

The question of vehicle inspection is similarly confronted by the problem of poor understanding of the effects of age and maintenance on vehicle components as safety factors. The fact is that the majority of states do not inspect their vehicles; many of those that do, inspect only once a year. What to inspect for, who shall inspect and how, are difficult but important questions. In view of the rejection rates of some of the jurisdictions that do inspect-fifty-five per cent of cars inspected rcjected on brakes in Pennsylvania, nine per cent in West Virginia-we may wonder if we know what we are doing or ought to do in inspection.

The insurance area is a total void but nonetheless of vital concern. We can ask many questions about the contribution of the various plans of automotive insurance but there are no clear-cut answers. It is fairly clear that the function of this insurance is to transfer the risk of loss, but the hidden questions concerning the effect of this transference on the loss rate itself are presently unanswerable.

\section{F. What Can Be Done?}

In summary, the state of our knowledge is poor. There is little that can be said definitively about the contribution of the various factors affecting highway safety. Few measurements are available to describe many of the factors such as vehicle condition and driver behavior widely believed to be significant ingredients of a safe transportation system; much that has previously been held as fact appears instead to be myth. It is clear that a greatly expanded effort is needed to learn more about accidents themselves by closer observation and study of accidents, near-accidents, 
and traffic operations in general. Increased attention is also needed to formulate, evaluate, and test a variety of remedies for this problem.

To be sure, there are many things that can be done and should be done almost at once or while we wait to find the remedies of choice. These short-term fixes to the system are defensible because they either remedy obvious accident-creating flaws in the present system or are available at little or no cost, or both. It is not possible to present a complete list of such quick fixes, but clearly this list would include many of the recently announced federal standards: night lights to make vehicles visible from the side; prohibition of sharp body features; dual braking systems; passenger restraint devices; and interior padding. Most such quick fixes are to be made on the vehicle; changes in the environment and in the driver tend to be less clear in their effectiveness and more costly in their application, and are therefore in more urgent need of immediate and intensive study and evaluation.

\section{$\mathrm{V}$}

\section{The Distrubution of Accident Losses}

The systems view of highway safety, as summarized in the foregoing, leads to some important conclusions relevant to questions of public policy now being formuláted.

Public interest in traffic safety developed slowly in the early 1960s; public inquiry into the matter reached a peak with the Senate investigations held in the summer of I965. At that time, the public press and various privately published monographs expressed alarm at the rising accident and fatality rate, attributing much of the rising accident rate to indifference on the part of the automobile industry, public officials, insurers, and others directly or peripherally associated with the automotive transportation system. This public inquiry led to the legislation which in 1966 created the National Highway Safety Bureau, ${ }^{9}$ through which the federal government seeks to promote changes in vehicle design and driver registration intended to limit or diminish the hazards of the highway. Thus far, most of the federally directed changes have been in the form of standards for new automobiles: lights, seat belts, tires, specifications on windshield thickness, and the like. In the year or more since the creation of the federal agency there has been an astonishing decline in the public attention given to the traffic safety problem. Whereas throughout 1966 one aspect or another of the subject was covered almost daily in the public press, today the subject is rarely to be found in any of our news media. This silence, of course, should not be mistaken for indifference. It may be nothing more than a pause in the

\footnotetext{
${ }^{8}$ Hearings on Traffic Safety Before the Subcomm. On Executive Reorganization of the Senate Comm. on Government Operation, 8gth Cong., Ist and 2d Sess., pts. I-4 (I966).

The National Traffic and Motor Vehicle Safety Act of 1966, 80 Stat. 718, and the Highway Safety Act of 1966,80 Stat. 73I, are now both administered by the National Highway Safety Bureau under the Department of Transportation Act, $\S_{3}(\mathrm{f})(\mathrm{I})-(3), 80$ Stat. 93 I (1966).
} 
protest to allow the legislative and other programs of traffic safety to produce the results the public seeks.

One part of the public protest, however, remains in view and is currently receiving a great deal of consideration by various public, governmental, and legislative bodies. The equitable distribution of accident losses is currently a matter of much concern. ${ }^{10}$ The present system of property damage and liability insurance is not functioning satisfactorily, from the point of view of neither the insurance companies selling this insurance nor the public purchasing it. The difficulties now experienced with the present insurance system have their roots in a rising accident rate, a continuing increase in the costs for repairs and awards for injuries in these accidents, and the consequent increase in insurance costs. The unfavorable underwriting experience of the insurers has prompted responses by them to reduce their losses: more selective underwriting; differentiation of risks by age, place of residence, and occupation; and cancellation of policies of motorists deemed to be high risk on the basis of age and accident experience. Some of the more venturesome companies writing coverage for these higher risk groups, where permitted, have become insolvent, leaving many claims unpaid. The growing costs of insurance, therefore, pose a problem for both the insurer and the insured. The public is asking for relief in the price of insurance and is urging that the earnings on the insurance industry's investments be used to support its underwriting operations, which for more than a decade have not returned a profit to the insurance industry as a whole. Because of these underwriting losses, the insurance companies have asked for further increases in automobile insurance rates. Labor unions and other public organizations have opposed these rate increases. Further, they have urged the creation of a federal guaranty fund similar to the Federal Deposit Insurance Corporation to cover the obligations of insolvent insurance firms. Other public agencies are protesting the increased discriminatory practices of insurers as unfair. Clearly some modification of the present system of loss distribution is needed to remedy what all agree is an unhappy state of affairs.

The present insurance system is a massive one and an important component of our economy. The over I 200 firms that write automobile insurance in the United States collect some \$10 billion in premiums annually, representing some forty per cent of all writings in the property and liability field. Liability insurance (bodily injury and property damage) comprises some two-thirds of the total premiums collected in automobile lines.

Our automobile insurance system may be characterized as a liability system.

\footnotetext{
${ }^{10}$ See, e.g., R. Keeton \& J. O'Connell, Basic Protection for the Accident Victim (1965); A. Conard, et al., Automobile Accident Costs and Payments (1964); Calabresi, The Decision for Accidents: An Approach to Nonfault Allocation of Costs, 78 HARv. L. Rev. 7r3 (I965); Symposium, Changes for Automobile Claims, x967 U. ILL. L. FonUm 361-633; Calabresi, Does the Fault System Optimize Primary Accident Costs?, in this symposium, p. 429; and Dollars, Delay and the Automobile VICrim (Walter E. Mejer Research Institute of Law, I968).
} 
The hazard that is insured against is the possibility of being held liable in a court of law or some other administrative body for damages to another person, his property, or other interests. This liability system stems from the law of torts which basically developed out of the rulings of the courts, although legislatures have occasionally made important contributions, as in the case of workmen's compensation.

If a party to the accident can be found at fault, that is, to have either negligently or willfully caused the accident, then a claim can be honored-otherwise not. Such a system leads to expensive investigations and litigation for the settlement of these claims, which, together with a host of the other expenses attendant to its operation, permit the return of less than forty-five cents of the insurance dollar to accident victims. ${ }^{11}$ Not only is the system expensive. It is also slow, inequitable, and undesirably discriminatory, and it has a number of serious social hazards built into it.

A variety of alternative systems of loss distribution have been considered. Most have as their basic feature a change to a system of liability without fault. The so-called Keeton-O'Connell plan ${ }^{12}$ is the latest in the series of such proposals. The concept of liability without fault accords well with some of the facts established in the previously mentioned study of accident causes. The present insurance system focuses on the driver as the cause of accidents. The currently growing body of literature on the nature and causes of automobile accidents gives little support to the widely held notions that accident causes can be assigned or that fault can be identified in the vast majority of automobile accidents. Current indications are that the simple causes usually cited for individual accidents bear little resemblance to the truth. There are no reliable indicators of accident proneness (predisposition to a higher than normal incidence of accidents) that can be used with any validity to sort out high-risk drivers from the population. The indicators used for such sorting are so poor that to identify a driver whose future accident record would be worse than normal, some much larger number whose future accident experience would in fact lie in the normal range would similarly have to be labelled. ${ }^{13}$ Thus the change to a loss distribution system which treats automobile accidents as similar to the accidents experienced under workmen's compensation makes sense. If it can be shown in addition that such insurance would in fact cost the public less, return more of the premium dollar in claims, reduce court congestion, permit the insurance companies a profit on their underwriting, and provide a more equitable distribution of the claims dollar, then such a change is clearly in order.

\footnotetext{
${ }^{11}$ Conard, Remarks, 1967 U. ILL. L. Forum 440.

${ }^{12}$ See R. Keeton \& J. O'Connell, Basic Protection for the Trapric Victim (1965), latcr modified slightly by the authors in Keeton \& O'Connell, Basic Protection Automobile Insurance, $1967 \mathrm{U}$. ILL. L. FORUM 400.

${ }^{13}$ See Versace, The Driver and Safety, in Traffic Safety, A National Problem 25.46 (ENo Foundation for Highway Traffic Control ed. 1967).
} 
SUMMary

Safety has been defined and described as a systems concern. Accidents are a manifestation of systems failure and are, therefore, a form of pathological behavior of the system. Looking at the system as an interconnected and an interdependent collection of hardware, people, procedures, and environment we find it difficult to describe the causes of accidents in simple terms or to ascribe them to components of the system. A review of the facts on accident causes in the automotive transportation system makes this quite clear. Our present state of knowledge does not let us isolate these causes in the simple terms usually discussed in the popular literature. The systems analysis approach to the traffic safety problem requires careful consideration of a variety of programs intended to reduce the hazards of the system as they exist in the vehicle, the driver, the environment, or the legal and regulatory features of the system. The costs of any remedy and the benefits provided in terms of the reduction in economic and social losses attendant to accidents must be carefully considered in selecting the remedies to be applied. An area of current concern in traffic safety is that of the distribution of accident losses. The present system of privately supplied property damage and liability insurance is almost universally considered unsatisfactory and a variety of modifications of the system are now under consideration. From a systems point of view a change to a loss distribution system based on the concept of liability without fault can be endorsed. 